\title{
About Balancing Problem in DETERMINIST CASE
}

\author{
Coculescu, C.
}

Abstract: Technical line balancing is a mean of economic efficiency increasing of some industrial activities. Essentially, to balance a technical line means to organize human operator's activity, to establish manufacturing flux, to project the line so to minimize equipments and operators' pause time, having a use of these as good as possible. In this work we'll present balancing problem for a technical line wherein an only model of a product is assembled, phase operating times are established and the operating rhythm of the line is fixed. We'll also make some regards about the ways for solving the problem and we'll describe an algorithm of simulation of a technical process, relied on random generation of the main characteristics of working phases, which will be considered in solving balancing problem.

Key words: technical line balancing, workstation, operating time, simulation
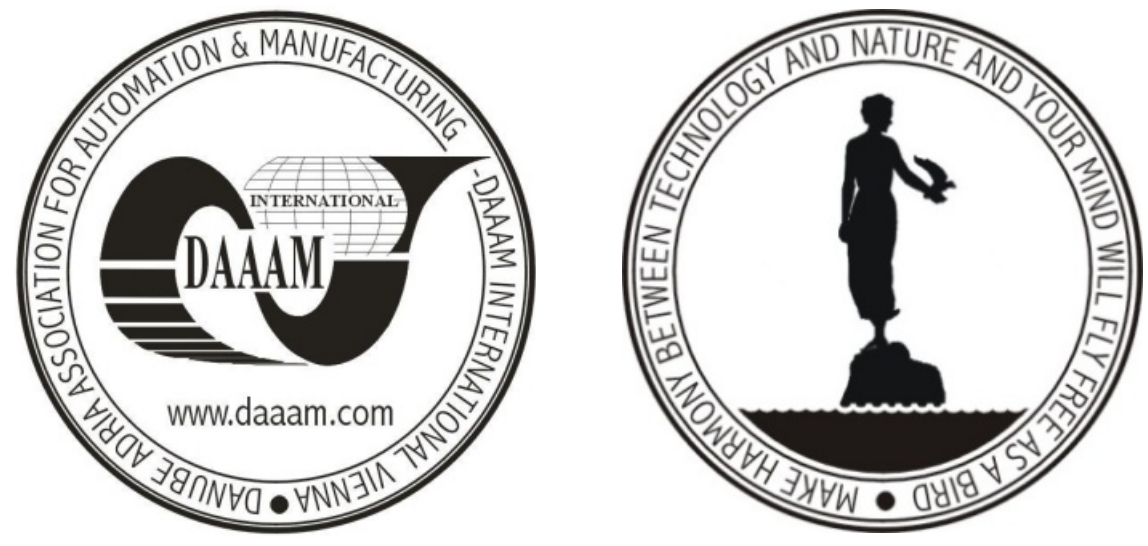

Authors' data: Senior Lecturer Ph.D. Coculescu, C[ristina], Romanian-American University, Expozitiei Avenue, 1B, District 1, 040503, Bucharest, Romania, cristina_coculescu@yahoo.com

This Publication has to be referred as: Coculescu, C[ristina] (2009). About Balancing Problem in Determinist Case, Chapter 45 in DAAAM International Scientific Book 2009, pp. 443-452, B. Katalinic (Ed.), Published by DAAAM International, ISBN 978-3-901509-69-8, ISSN 1726-9687, Vienna, Austria DOI: $10.2507 /$ daaam.scibook.2009.45 